Article

\title{
The Hybrid Space of Collaborative Location-Based Mobile Games and the City: A Case Study of Ingress
}

\author{
Ulysses Sengupta, Mahmud Tantoush *, May Bassanino and Eric Cheung \\ Manchester School of Architecture, Manchester Metropolitan University, Manchester, M15 6BH, UK; \\ E-Mails: u.sengupta@mmu.ac.uk (U.S.), mahmud.tantoush@mmu.ac.uk (M.T.), m.bassanino@mmu.ac.uk (M.B.), \\ p.cheung@mmu.ac.uk (E.C.) \\ * Corresponding author
}

Submitted: 17 July 2020 | Accepted: 2 September 2020 | Published: 15 December 2020

\begin{abstract}
Structural changes in the way we live and interact in cities are occurring due to advances in mobile communication technologies affecting everyday practices. One such practice, at the forefront of digital technology adoption, is digital gaming or play. Location-based mobile games (LBMGs), such as Pokémon Go and Ingress have surged in popularity in recent years through their introduction of a new mode of play, employing mobile GPS and internet-enabled technology. Distinguished by their embedded GIS, LBMGs can influence how people play, interact with and perceive the city, by merging urban and virtual spaces into 'hybrid realities.' Despite the popularity of such games, studies into how LBMGs affect urban dweller interactions with each other and the city have been limited. This article examines how the digital interface of the large-scale collaborative LBMG Ingress affects how players experience and use the city. Ingress is a collaborative hybrid or locationbased game that uses GPS location information from smartphones, Google maps, and Google POI to create virtual gameplay environments that correspond to and interact with other players and the city. The methodology cross-references the MDA framework from game studies (Mechanics-Dynamics-Aesthetics) within the urban mobility, sociability and spatiality characteristics of the hybrid realities theoretical framework. In this article, we explore how Ingress (re)produces hybrid space through deliberate design of interface game elements. By applying this analytical approach, we identify the game mechanics and their role in producing a hybrid gameplay environment with impacts on social and mobility practices altering the perception of and engagement with the city.
\end{abstract}

\section{Keywords}

augmented reality; collaborative LBMG; digital interfaces; hybrid spaces; Ingress; location-based mobile games; MDA framework; urban space

\section{Issue}

This article is part of the issue "Digital Geographies and the City" edited by Wen Lin (Newcastle University, UK).

(C) 2020 by the authors; licensee Cogitatio (Lisbon, Portugal). This article is licensed under a Creative Commons Attribution 4.0 International License (CC BY).

\section{Introduction}

Spatial planning is currently being confronted with unprecedented change, which is taking place at the interface between traditional environments and the rapidly evolving virtual world....Change under discussion here is partially digitally constructed and virtually produced, affecting and transforming space and place. No one knows precisely what the developments that emerge from this hybrid space between the material and virtual worlds will precipitate. (de Roo \& Yamu, 2017, p. 11)

Digital technologies are increasingly becoming part of our daily existence, and their meditating influence on our everyday practices in city life is causing a fundamental transformation of culture and practice (Ash, 2015; Castells, 1996; Manovich, 2001; Rabari \& Storper, 2015). Technological advancements in both software and hardware technology have led to a certain type of digital 
games called location-based mobile games (LBMGs) or hybrid reality games (HRG). Such games employ augmented reality as a technological aspect within the hybrid realities theoretical framework. While there is a distinction between the definition of HRG and LBMGs in literature, we use them interchangeably in this article. The spatiality of digital games, in general, have evolved from simple two-dimensional to complicated three-dimensional worlds (Shaw \& Warf, 2009), and now to complex (relational) hybrid multi-dimensional spaces (de Souza e Silva \& Sheller, 2014). Hybrid space can be understood as a space between material and virtual worlds (de Roo \& Yamu, 2017, p. 11). A more nuanced understanding rejects the binaries to recognize a new logic of hybridised space emerging as a product of interrelations and entanglements between spaces (de Souza e Silva, 2009; McLean, 2020, p. 3). In a similar vein, Montola (2005) points to the blurring and breaking of traditional boundaries leading to social, temporal and spatial expansions influencing ordinary life.

Distinguished by the use of embedded GIS, LBMGs influence how people play, interact and perceive the city, by merging urban and virtual spaces into what has been termed 'hybrid realities' (de Souza e Silva, 2009; de Souza e Silva \& Hjorth, 2009). These games include the location of players, transmitted through GPS signals, into the gameplay so as to include speed, heading and orientation (Winter et al., 2011). A player's avatar in the map-based virtual world corresponds to their geographical location, enabling particular interaction possibilities through the player's smartphone interface and in the physical city space simultaneously. These games, as with other mobile technologies, affect urban experiences encountered in cities (Colley et al., 2017; Hjorth \& Richardson, 2017). Yet the question of how the design of the game interface and game components define the space of interactions (spatiality), patterns of movement through the city (mobility) and social interactions in urban spaces (sociability; de Souza e Silva, 2009), has not been clearly understood. This article uses the game Ingress as a case study of a collaborative LBMGs to understand how the design of the game mechanics/interface affects space and urban practices in the city. This study relates to the broader concern of understanding the spatial implications of digital mediation in geography (Kinsley, 2014).

Our argument and analysis is presented through the following logic. The following sections provide a selective review to position current debates on the mediating influence of mobile technologies in the city and hybrid spaces. After this, a new analytical framework relating game design to hybrid reality conceptual areas is developed. The case study is introduced through a brief description of the game and gameplay, before the analytical approach is applied. The article concludes with a presentation of the analysis and a discussion on game design and new interactions and practices.

\section{Hybrid Reality Games and the City}

The ever-increasing influence of digital devices and software on almost all practices such as work, leisure and travel has led to what is termed 'the digital turn' in geography. This has been categorised into geographies produced through, by and of the digital (Ash, Kitchin, \& Leszczynski, 2018). While this categorisation is useful to understand how the digital interacts with the practice of knowledge production in geography (through the digital), relational space (by the digital), and virtual geographies/space (of the digital), the spatiality of mobile technology cannot be separated in this manner due to the blending of the virtual and the physical. A new logic of space, merging geographies of and by the digital space, or virtual and relational space, arise due to mobile technology (de Souza e Silva, 2009; de Souza e Silva \& Sheller, 2014).

An increasingly popular lens to explore how new mobile digital technology influences urban behaviour and experience is based on the theories of 'digi-place' and 'code/space.' While the latter focuses on how code and space are mutually constituted, the former builds on this theory to explore how urban places are experienced through the mapping and ranking of information in cyberspace (Dodge \& Kitchin, 2004; Kitchin \& Dodge, 2011; Zook \& Graham, 2007). Both are centred around how code 'transduces' space and discuss new hybrid compositions that merge the cyber and the physical. However, the emphasis here is placed either on the changing nature of urban place, through augmented urban experience, or on the production of space through code.

In contrast, de Souza e Silva's (2006) theoretical framework of hybrid spaces/realities examines space through the blurring of traditional boundaries between the physical and the virtual, as a result of the shift to mobile interfaces from static ones. This concept focuses on internet and GPS-enabled mobile technologies, which alter and create new forms of engagement and experience in cities, developing a unique lens to view and examine different digital interfaces. The concept of hybrid spaces is strongly related to urban gaming, specifically LBMGs or HRGs. De Souza e Silva (2009, p. 405) defines HRGs in the following manner:

By creating a unique way of connecting players, and players to the play space, these games define a new logic of game space, which raise issues about our perception of urban spaces, the daily mobility through the city, and the relationship between serious life and playful spaces.

The three main characteristics utilised by de Souza e Silva to analyse HRGs in relation to urban interactions and experiences are spatiality, and through this, mobility and sociability (de Souza e Silva, 2009). The spatiality characteristic refers to the nature and logic of hybrid space or 
reality that emerges from the mobile game/technology, and how this changes the interactions and experiences within, and of the city (de Souza e Silva, 2009). Mobility, as a new paradigm in urban planning, geography and the social sciences more generally (Sheller \& Urry, 2006), looks at how players of such games change their patterns of movement and practice of travel in urban space by interacting with the game. The effect of LBMGs on movement and mobility have also been discussed in the context of Pokémon Go (Evans \& Saker, 2019; Gong, Hassink, $\&$ Maus, 2017).

The sociability characteristic, building on the theory of urban sociability and ontology of play (Fink, 1974; Lehtonen \& Mäenpää, 1997) examines the social interactions that are facilitated by the interface, movement and collective actions of players. The spaces that are (re)produced through mobile technologies, such as LBMGs, can be explored by analysing the digital interface through gameplay and observations of how players interact with the platform or game (Ash, 2015; de Souza e Silva, 2006; Manovich, 2001). For example, de Souza e Silva (2017) has used this approach to highlight how Pokémon Go lacks the sociability characteristic due to the lack of direct interaction between players as a result of the interface design. Ingress includes a different set of game mechanics, narrative and design that produces a different hybrid space with different effects on the city, which can be examined using a similar approach.

Within the context of the urban and spatial planning, the relevance of LBMGs lies in how such games change the practices of city dwellers, and how such platforms hold the potential to foster greater civic engagement and urban participation. As planning has evolved into planning as a 'reasoning process' through collaboration, so have the technology and tools utilised (Foth, Bajracharya, Brown, \& Hearn, 2009). The potential of games in participatory planning practices, as new tools or technologies for reasoning and collaboration, has been debated and discussed extensively. In recent years, there has been an increasing trend towards using various forms of digital games for participatory planning (Ahlqvist \& Schlieder, 2018; Gordon, Schirra, \& Hollander, 2011; Poplin, 2011, 2014). These games are designed for community deliberation (Gordon \& Manosevitch, 2011) and have typically been 'serious games,' or Public Participatory GIS (Gordon \& Baldwin-Philippi, 2014; Poplin, 2011). However, such platforms have been criticised as one-off 'workshops' that are poorly designed and lack immersive and engaging features for creating ongoing involvement and engagement, and thus less effective than games designed for play (Gordon et al., 2011).

The specific challenge here is to understand how the design of the LBMG Ingress, a game not designed for planning, (re)produces a hybrid reality as an altered spatiality affecting the mobility and sociability of urban dwellers, and fostering engagement and participation, that 'serious games' in planning have not achieved. This requires a formal approach for the analysis of HRGs or LBMGs, breaking down game design components to examine how their mechanics (re)produce the hybrid space. To achieve the desired analysis we adapt the MDA analytical model from game studies (the MechanicsDynamics-Aesthetics framework) to cross-reference the essential and particular characteristics identifiable within HRGs. The following section provides additional details of the analytical approach utilised in this article.

\section{Analytical Approach}

A common analytical framework to examine how the specific design of mobile interfaces, particularly LBMGs, can affect urban practices and experience is non-existent in literature. An interdisciplinary approach to examining the digital interfaces, such as Ingress in our article, is necessary to bridge theories and methods of geography, social theory, media and cultural studies, and game studies (Ash, 2009, 2013). This follows a shift in emphasis across research on gaming more broadly, in which digital games are increasingly situated in relation to everyday practices and connections are drawn between game studies and a range of other disciplinary contexts (Apperley \& Jayemane, 2012). In this article, we combine essential characteristics from the theoretical framework of hybrid realities with the MDA analytical model from game studies. This allows us to explore how the designed elements of our case study game affect the spatiality, sociability and mobility of players (engaged urban dwellers), through the hybrid reality enabled by the game.

The MDA analytical model was developed by Hunicke, LeBlanc, and Zubek (2004). This wellestablished framework aims to bridge the gap between game research, design, development and criticism (see Figure 1). The MDA framework has been previously used to demonstrate value and usefulness of existing gamesby breaking them into analysable components-in the context of urban planning (Ashtari \& de Lange, 2019).

From Hunicke et al. (2004, p. 1723), mechanics describes "the particular components of the game, at the level of data representation and algorithms," dynamics refers to "the run-time behaviour of the mechanics acting on the players' inputs and each others' outputs over time" and aesthetics refers to "desirable emotional responses evoked in the player, when she interacts with the game system." The aesthetics component of the model uses a dedicated vocabulary that includes: sensation, fantasy, narrative, challenge, fellowship, discovery, expression and submission. Each of the three components is used as a separate 'lens' to view the game but are causally linked.

In this framework, players experience the game through aesthetics as a result of the observed dynamics whereas the designer of the game experiences the game mechanics first when designing the system. The consideration of both perspectives, from mechanics to aesthet- 


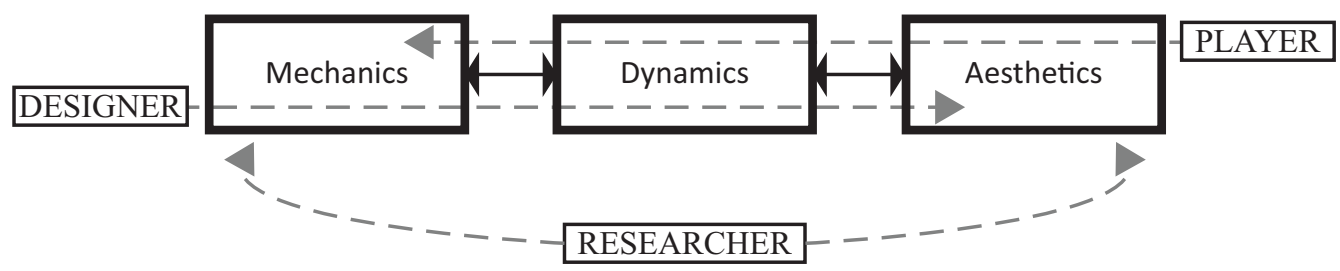

Figure 1. MDA model for game research, design and criticism. Source: Hunicke et al. (2004, p. 1723).

ics and vice versa, allows for research of the game to be undertaken. This model, when cross-referenced with the characteristics of hybrid realities (see Figure 2), presents a promising analytical approach for uncovering the 'black box' effects that game components might have on producing a new logic of hybrid space.

The methodology utilised follows visual research and observation methods that examine on-screen representations of how players interact with the game, other players, and the city (Ash, 2015; de Souza e Silva \& Sheller, 2014; Rose, 2016). A qualitative content analysis method from visual research is used here to help us reveal and analyse patterns within the large quantities of observable data (Lutz \& Collins, 1993; Rose, 2016) in the game.

Data were collected through immersion in the game over a three months period, with due attention given to covering different days of the week and different times of the day. Researchers participated as players in the game and conducted observations through this process rather than as non-participant observers. The three types of data collected are: (1) Notes on the game design, i.e., interactions with the game and through the game with other players and elements; (2) screenshots that were collected, processed and collated based on potential relevance to the conceptual areas of the hybrid realities theoretical framework; and (3) notes added to annotate the screenshots, making note of the various types of interactions and communication. The data were collected for gameplay interactions in Manchester, UK. The region provided sufficient gameplay activity due to the prevalence of culturally significant sites, corresponding to Ingress portals, and adequate population density. As resident researchers in the city, our direct involvement in gameplay interactions was possible.

The analytical process involved coding the data to categories identified in the proposed analytical framework. The framework combines a hybrid realities theoretical framework and the MDA analytical model. The resultant analytical matrix (see Figure 2) presents an opportunity to cross-reference two frameworks, to relate the designed elements of mobile game interfaces with characteristics of and enabled by hybrid reality spaces. This perspective enables bridging of theory and game design based on qualitative observation and coding rather than quantitative approaches based on game statistics, interviews or surveys. It is worth noting that, while examining the effects of the Ingress interface on the city and its dwellers is the aim of this article, technological determinism is not assumed. i.e., users are not reduced to 'puppets' that are influenced solely by the game mechanics (Ash, 2015, p. 9). This study positions technological advances against possibilities for changed behaviour.

As part of a multi-stage process, we initially position MDA based observables in relation to actions, behaviours and experiences of players within the new logic of the hybrid space (spatiality). A second step relates mobility and sociability of players-as urban dwellers - to the space of the city. The MDA analytical framework as incorporated in this approach requires a specific interpretation for use with LBMGs. Here, mechanics are considered to be the intentional design features of the game built around communication and

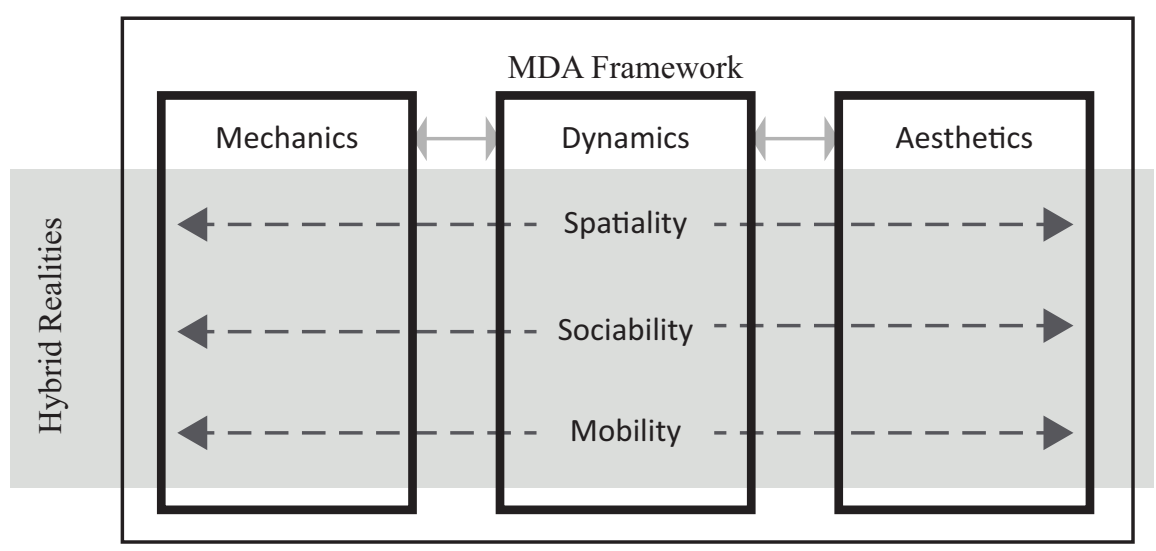

Figure 2. Analytical model combining the MDA model and hybrid realities theoretical framework. Source: Hunicke et al. (2004) and de Souza e Silva (2009). 
movement opportunities. Dynamics refers to the use of specific game design features contributing to individual or collective run-time behaviours. Aesthetics is based on gameplay incentive, i.e., what allures the players to play Ingress in the urban setting in specific ways.

\section{Case Study: Introduction to Ingress}

Ingress was launched in 2013 and presents an exemplar case study of collaborative LBMGs for several reasons. Ingress' game design embeds components for collaboration and socialising that are unique and different when compared with other LBMGs (Lee, Keating, \& Windleharth, 2017). Ingress had over 20 million global players according to reports by Niantic-the Ingress game developer owned by Google-in November 2018 (Niantic, 2018). Within the game, a 3D map-based virtual world that corresponds to real-world geography is interacted with through the interface to facilitate play. This gaming platform uses GPS location information from smartphones, Google Maps, and Google points of interest (POI) to bridge urban and virtual spaces. Players move through the physical environment of the city and their avatar in the game moves accordingly in the virtual
Ingress environment that is visible to them through their smartphone screens (see Figure 3).

\subsection{Game Narrative, Aims and Infrastructure}

The game narrative is developed around an alien resource called Exotic Matter (XM). Players of the game are split into two factions: The Enlightened, who believe XM will help to enlighten humanity; and the Resistance, who believe XM enables an alien entity to control human minds. Both factions are composed of real-world players who choose which faction to join. The opposing ideological factions seek to capture virtual 'portals' to control virtual geographic areas and prevent the other faction from taking control of the city. Portals are mapped to realworld heritage or cultural POI such as public works of art, landmarks, parks, etc. (Niantic, 2018). By linking portals together through a triangulation process, the competing factions can take over geographical areas to create 'mind fields' that can either enlighten the human population below (Enlightened) or protect the population from the threats of mind control (Resistance). Mind fields vary in sizes and can span across cities, countries and borders. The XM material is scattered across the city where
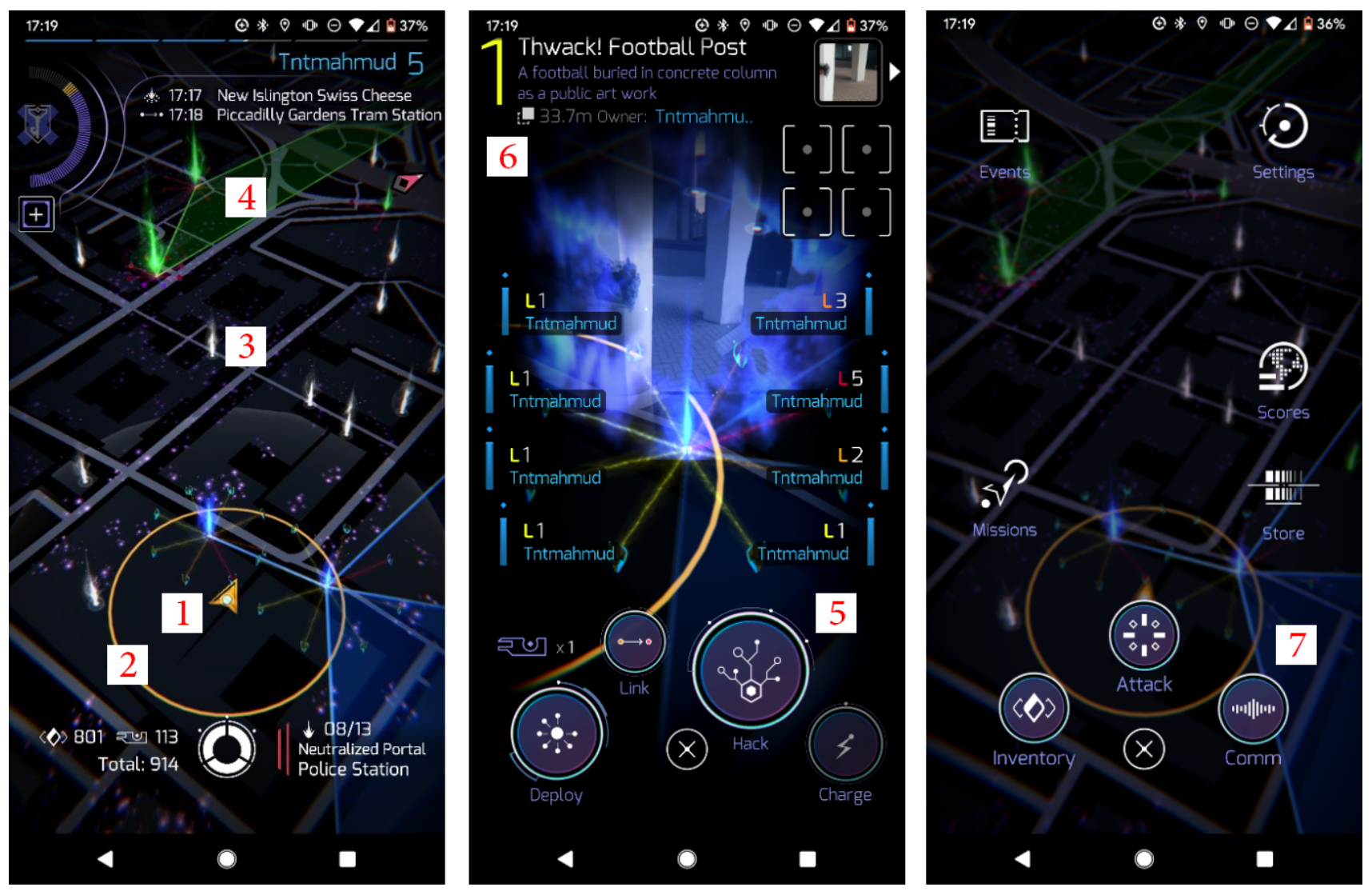

Figure 3. From left to right: Ingress 'Scanner' phone app for locating and collecting XM and portals; the status of portals and the real-world POI they correspond to-in this case, the 'Thwack!'; gameplay features such as communications, attacks, global scores, inventory, missions and events. Notes: (1) player's avatar, (2) gameplay interaction radius, (3) portals, (4) mind fields, (5) portal hack and deployment interface, (6) portal status and info (7) communication channel. The green portals or mind fields are captured by the Enlightened, and the blue portals or mind fields are captured by the Resistance. 
players can collect them to power weapons to attack or defend portals.

The main aim of the game is to control as much of the city as possible to alleviate the threat of control from the rival faction. Players play the game through their smartphone Ingress app, which acts as a 'Scanner' of XM material and portals embedded within their surrounding area. Players use this interface to attack and capture the opposing faction's portals and mind fields or defend and protect their own. The XM scanner app provides immediate contextual information related to portal capture or attack. To see the bigger picture of how the battle is unfolding, players use the Ingress Intel map (see Figure 4). This Intel map provides the players with a top-down view to coordinate and plan strategic attacks from a desktop internet browser. Ingress facilitates collaborative multiplayer play by providing communication channels and events where the Ingress urban communities can gather and exchange information for field operations.

Ingress' gameplay run-time behaviour enabled through the game mechanics is driven by a digital data environment or infrastructure. This is comparable to the digital skin of cities (Rabari \& Storper, 2015) in that this big data environment constructs a virtual city or reality. This also exerts influence on how urban mobility and sociability are impacted through the hybrid spatiality of the LBMG. The game designers, through unknown processes, provide a baseline top-down positioning of portals. However, players can also suggest new portal locations, comment on, rate and volunteer their local knowledge by describing and rating real-world POI that correspond to portals in the game (see Figure 5). This enables the possibility for an evolving game board through bottom-up processes between players and Niantic, who consider proposals based on their published guidelines for approval and portal criteria. The 'Wayfarer' tool introduced in October 2019 enables players of a certain level to nominate, peer-review and rate portals and places. In addition, Missions, a feature added in 2014, facilitates players suggesting and collaborating with others on missions by specifying certain times and portal tracks, or waypoints, to visit and interact with in specified ways. In order to keep the players up to date with the latest changes, Niantic publishes guidelines and offers support through their website for portal and other gameplay features (Niantic, 2020a).

\section{How the Design of Ingress Affects the Logic of Hybrid Spatiality and Links to Urban Mobility and Sociability}

The analytical approach used in this research enables grouping of mechanics, dynamics and aesthetics within the game design as drivers of gameplay logic and player interaction through the (re)production of hybrid 'spatiality.' This section presents observable links between the virtual interactions, urban mobility and sociability in the physical and social spaces of the city. It should be noted that hybrid realities necessitate an inseparable understanding of virtual and city spaces and that attempts to extricate the two to observe the impact of one on the other is difficult due to their intertwined nature. Each section presents the findings of the MDA model as applied to each of the hybrid reality characteristics (see Figure 6).

\subsection{The (Re)Production of Hybrid Reality Game Space (Spatiality)}

The spatiality of the game is shaped by the mechanics designed into it, along with the dynamics and aesthetics that emerge from the gameplay. The specific combi-

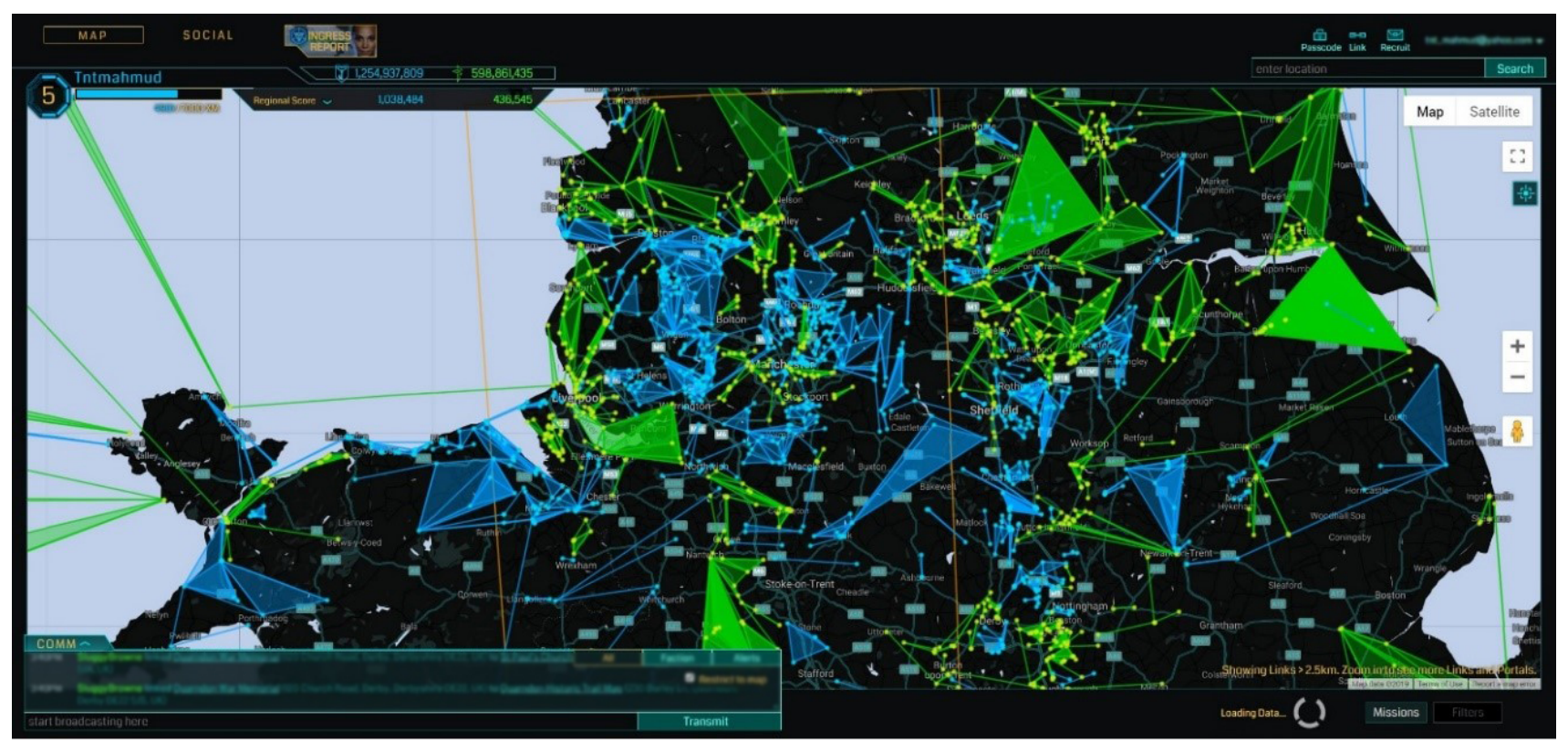

Figure 4. Screenshot of Ingress Intel map showing the aggregate outcomes of the battle for portals in the West and East Midlands region of the UK. 


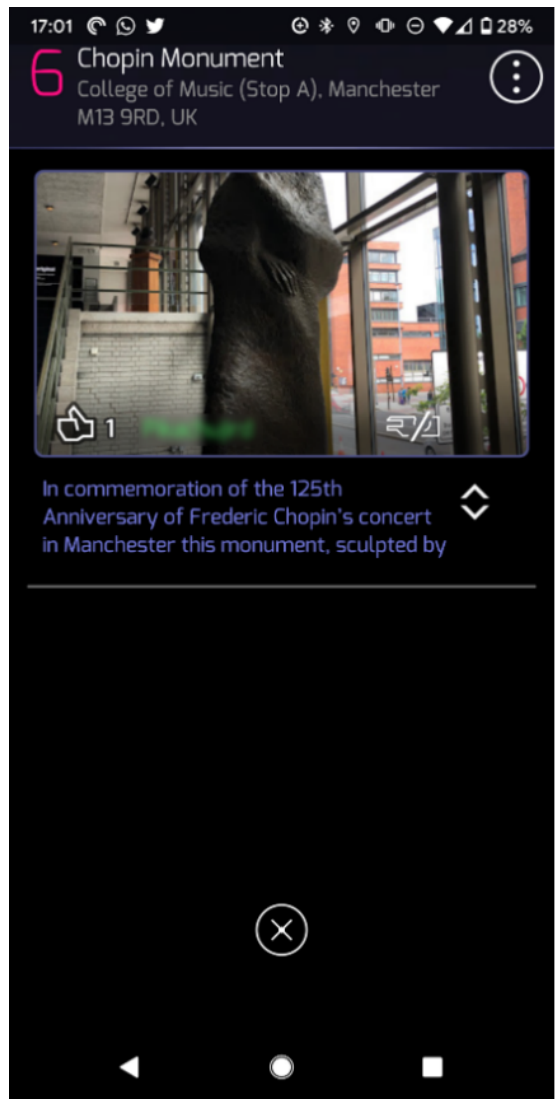

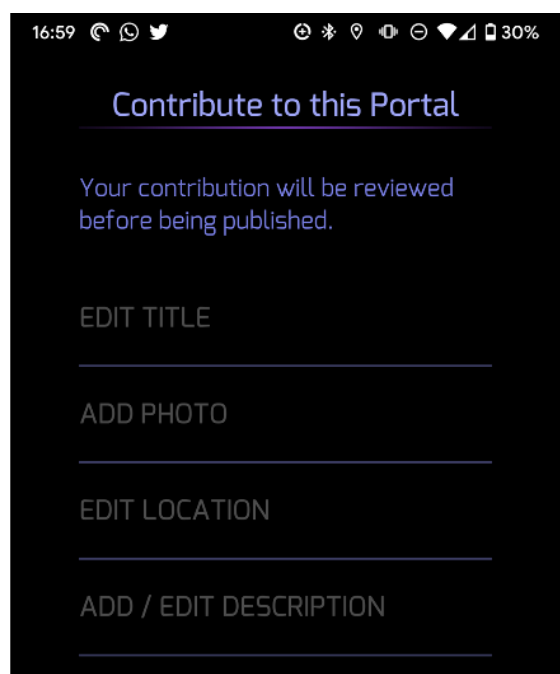

REPORT INVALID PORTAL

Figure 5. From left to right: Ingress' volunteered portal information from smartphone application-portal local knowledge contribution, rating and POI Images; portal contribution interface; player gameplay history and data.

nation of elements constituted under these categories defines the unique hybrid reality game space and the ways in which players interact with it and in it.

The most significant game mechanics (components, data representation, algorithms) contributing to this spatiality have been observed to be:

Mechanic 1: The co-existence and co-location of virtual and city spaces and game elements (portals/ territories) creates a hybridised experience of the city.

Mechanic 2: The ability for players to change the game board bottom-up through proposals of new virtual elements and supporting information about the physical spaces these will be associated with.

Mechanic 3: The locally limited and live augmented experience of the proximity scanner allowing interaction with other players and virtual game elements within a player's immediate vicinity, while on the move.

The primary contributing game dynamics (the run-time behaviour of the mechanics acting on the players' inputs and each others' outputs over time) observed are:

Dynamic 1: The aim of territorial acquisition within the hybrid spatiality of the game alters the reading of the physical territories of the city, by layering them with altered values and qualities related to assumed control and need for strategic location-based actions.

Dynamic 2: Contribution of local area knowledge in support of virtual elements constantly changes the game board. There is an ongoing process of city information being (re)produced within the virtual game board as players can directly contribute local knowledge of POI and local heritage, more closely aligning the material and the virtual. This process of "knowledge contribution' is what Winter et al. (2011) refers to as spatial knowledge acquisition of LBMGs and can also be considered a form of Volunteered Geographic Information (VGI; Goodchild, 2007).

Dynamic 3: Augmentation of unexplored virtual spaces in the game creates an impetus for players to explore and play previously unexplored spaces in the physical city. The dynamics of mapping and rating transforms how places in the physical city are perceived and navigated (Zook \& Graham, 2007).

The aesthetics (desirable emotional responses evoked in the player when interacting with the game system) observed related to the formulation of the game space are: 


\begin{tabular}{|c|c|}
\hline & Mechanics \\
\hline $\begin{array}{l}\text { Spatiality - } \\
\text { production of } \\
\text { hybrid space } \\
\text { in relation } \\
\text { to urban } \\
\text { experience } \\
\text { and practice }\end{array}$ & $\begin{array}{l}\text { 1) Co-location of real physical } \\
\text { spaces and virtual game } \\
\text { elements (portals/territories) } \\
\text { creating a virtually augmented } \\
\text { physical experience of the city } \\
\text { 2) Bottom-up portal } \\
\text { suggestions, comments, } \\
\text { ratings and contribution of } \\
\text { local knowledge } \\
\text { 3) "Scanner screen" } \\
\text { smartphone application }\end{array}$ \\
\hline $\begin{array}{l}\text { Sociability - } \\
\text { social } \\
\text { interaction } \\
\text { related to } \\
\text { playfulness, } \\
\text { experience, } \\
\text { unpredictability } \\
\text { and surveillance }\end{array}$ & $\begin{array}{l}\text { 1) Channels for within faction } \\
\text { and cross-fraction } \\
\text { communication affected } \\
\text { by distance } \\
\text { 2) Incessant } 24 / 7 \text { gameplay } \\
\text { possibilities and game alerts }\end{array}$ \\
\hline $\begin{array}{l}\text { Mobility - } \\
\text { patterns, mode } \\
\text { of transport } \\
\text { and experience }\end{array}$ & $\begin{array}{l}\text { 1) Avatar movement in virtual } \\
\text { and real space to capture and } \\
\text { link portals with decay function } \\
\text { 2) The Intel Map: } \\
\text { dashboard-like gameplay data } \\
\text { display with incorporated } \\
\text { communication channels }\end{array}$ \\
\hline
\end{tabular}

\section{Dynamics}

1) Altering the reading of the physical territories of the city, by layering it with altered space qualities as a result of the territorial acquisition aim of the game

2) Ongoing process of real city information being altered within the virtual environment as players can directly contribute local knowledge of $\mathrm{POI}$ and local heritage

3) Augmentation of new unexplored virtual space onto the urban space changing the urban experience and generating impetus for exploration

1) Encounters through tactical and collaborative gameplay, development of new social networks, external social media groups and physical meetings in the city

2) Continuous gameplay opening up possibilities of co-ordination with other daily practices and spontaneous interaction with the game throughout the day

1) Players move through the real city in order for their virtual avatars to capture virtual portals or otherwise interact with game

2) Dynamics of strategic collective movement and communication informed by desktop intel map and filters

\section{Aesthetics}

1) Challenge of capturing important territories and active engagement

\section{2) Discovery and} contribution of city knowledge cultivated through sense of useful contributions

3) Sensation through the accidental encounters and live competitive game play

\section{1) Fellowship through} collaboration to achieve common gameplay objectives

\section{2) Sensation of} unpredicted urban social encounters and continuous gameplay

1) Fantasy of role playing that drives collaboration

2) Narrative of two opposing factions impacts on the mobility practices in order to gain competitive advantage

Figure 6. Results of applying the new analytical matrix, combining hybrid reality categories and MDA.

Aesthetic 1: The continuous challenge of capturing and retaining control over territories drives the engagement between players and the game. It engages players with the combined virtual and physical space of the game and the city in a process that does not stop when players are not actively partaking in the game. Hence, the territory of the game board is dynamic and requires active engagement.

Aesthetic 2: Discovery-through uncharted territory-of new elements and a sense of useful contribution, cultivated by allowing players to re-assert their values and meaning of place into the game, when in accordance with Niantic's guidelines and standards. Here research of the physical city, POI such as works of arts or landmarks and local knowledge, have a role in a player's ability to contribute to the evolving game board.
Aesthetic 3: The sensation-changes to the urban experience-of seeing the actions (not location) of local players amongst other game elements creates a sense of accidental encounter, intimacy, excitement and live competitive gameplay, making the hybrid game space dynamic at a personal scale. A parallel and reframing of this sensation as 're-enchantment' can be found in other LBMG studies (Fragoso \& Reis, 2016; Klausen, 2014).

\subsection{New Opportunities for Sociability}

The particular spatiality of the game results in specific types of observable sociability within the hybrid space but also spilling over into social practices within the city.

The observable game mechanics encouraging and/or enabling specific aspects of sociability are: 
Mechanic 1: The availability of channels within the game for communication with other players of your faction and also from the opposing faction. The filtration of these communications based on current geographical location and distance play a role in centralising the importance of immediate locality and proximity to others.

Mechanic 2: The incessant nature of the game running and changing no matter whether a player is actively engaged or not, alongside alerts that appear on the player's smartphone even when the Ingress app is not open, results in an overlap with the time and space of other daily practices.

The transmutation of space within Ingress occurs partially through player interactions and hence is not wholly controlled by either the game designer or single players, affecting sociability dynamically and unpredictably. In the context of this, the observed dynamics of the game driving aspects of sociability are:

Dynamic 1: The tactical and collaborative nature of the game, which results in the creation of additional social networks, external social media groups and even physical meetings in the city. As a demonstrative example, while participating in the game, the authors were invited to and joined a group on Google Hangouts with 91 players from the local area. Such groups were observed to be commonplace based on observable discussions on gameplay operations. The authors were also invited to virtual teleconferencing events that took place over zoom, where players could choose to be identifiable to each other, and sometimes undertake quizzes.

Dynamic 2: The continuous gameplay means that players are not involved in a binary on/off situation, but rather scale their input based on the possibilities of co-ordination with other practices and spontaneously interact with the game throughout the day. Collaborative LBMGs, in this case, reinforces Montola's (2005) argument of the 'expanded magic circle of play,' where the boundaries between play and everyday become less defined.

The aesthetics observed in relation to sociability are:

Aesthetic 1: The growth of fellowship, through the development of faction identities and relationships (friendly and adversarial) originating from the gameplay, towards achieving common collective goals through strategic collaboration. The player-to-player interaction enabled by locality and distance link to sociability in relation to playfulness, unpredictability and surveillance (de Souza e Silva, 2009). The playfulness of the game gives rise to social and spatial negotiation leading to competitive and unpredictable behaviour, and the surveillance or monitoring of how others are playing the game. From our case study, an anecdotal example of sociability was observed when a certain player was observed challenging players from the opposing faction regarding control over a certain locality. The communication between the players involved playful invitations and challenges such as "you can try if you can." The attacking players coordinated their attempts to acquire the territory but eventually failed. This interaction eventually raised suspicions for the losing faction leading the attacking players to ask "have you got 2 accounts?," which was confirmed by the defending player that stated "ha ha ha, ya seen me." The observed behaviour of players involved unpredictability, surveillance of the other and playfulness.

Aesthetic 2: The associated sensation-the experience of virtual game elements augmenting the real world-of sociability as a result of the fellowship aesthetic is a particular strength of Ingress, in addition to the surveillance of other player actions on screen and sometimes physical encounters, contributes to the sensation of playfulness and unpredictability as we have observed. As mentioned previously, our observations also found that the design of ingress fosters unique collaborative gameplay and socialising elements (Lee et al., 2017).

\subsection{Entangled Digital and Physical Mobility}

The spatiality of the LBMG requires players to move through the physical space of the city, and collaborate on strategic objectives in order to achieve goals.

The two most significant game mechanics related to the mobility of players are:

Mechanic 1: The avatar of the player within the virtual game environment mirrors the movements and location of the player in the material physical environment. This means that playing the game actively requires movement through the city.

Mechanic 2: In addition to the mobile interface on the smartphone, there is also a desktop Ingress Intel map of the unfolding gameplay providing a big picture of the state of play. Players use this top-down view to coordinate and collaborate multiplayer movement towards the achievement of strategic goals.

The main game dynamics affecting mobility in the city are:

Dynamic 1: Players move through the physical spaces of the city in order to capture virtual portals with their virtual avatar or otherwise interact with the game. The portals have a decay function, meaning that players have to repeatedly visit their locations to main- 
tain and charge them. This aspect has an impact on the mobility patterns of the players, who often seek to capture or defend portals and mind fields around their residential or work localities. The prevalence of this territorial behaviour was clear in our observational data. Players, in a number of examples, communicated or observed other players living or working in the neighbourhood by the number of portals they had captured. The player pseudonym for captured and maintained portals are visible to other players (see Figure 3). Players were often observed to post messages such as "yea, I only live around the corner from the library" to build local networks for tactical advantage. However, players also go beyond their work and home localities to participate in collective attacks with other players of the same faction when deemed strategically necessary. In addition to this, game missions suggested by players themselves challenge other players to seek out culturally significant sites that go beyond their familiar localities.

Dynamic 2: The desktop-based 'Intel map' allowing overviews of the wider state of play incorporates various levels of data aggregation and tools to filter and analyse different situations. The communication channels to locally relevant players result in the dual dynamics of strategic collective movement of multiple players in the city and the reality of them navigating the immediate built environment and available modes of transport. The differences between the phone and desktop screens are shown in Figure 3 and 4 respectively. A player's mode of travel affects both patterns and speed of movement. Players on foot have more local travel patterns and can go into parks and places where cars cannot, while travel by car allows for speed and distance, but is restricted by city infrastructure.

The game aesthetics affecting mobility are:

Aesthetic 1: The simulated fantasy-the make-believe factor-of a greater purpose based on collective endeavour playing a role in mobility patterns of players and the motivation to undertake trips to achieve collective goals.

Aesthetic 2: The rivalry created by the game narrative - the drama of gameplay-of two opposing factions impacts on the mobility practices of players as they competitively change locations in attempts to alter the geometric on-screen representations of mind fields that are the measure of winning or losing the game. Several observable examples illustrate the dynamics driven by portal locations and aesthetics leading to both unpredictable and organised urban encounters. Players from cross-factions could be observed to challenge each other through the communication channels provided within the game to battle over certain portals/areas. Subsequent com- munication through these channels also highlighted accidental encounters in the city with "was that you..." messages. Online adverts also elude to these 'accidental' encounters (Niantic, 2020b)

\section{Discussion}

This section discusses the key game mechanisms, their effects and altered practices in the city. The observations in the previous section illustrate how game design affects the behaviour and experience of players. The analytical approach also allows the identification of key mechanisms affecting gameplay, leading to altered practices in the city. The primary areas of impact identified are (1) altered perceptions/readings of the city and (2) altered engagement with the city. These, in turn, lead to altered practices in urban movement and social collaboration.

Ingress has incorporated a potent combination of innovative mechanisms based on a wide range of possibilities for LBMGs. Its hybrid spatiality co-locating material and virtual elements in the city blurs the game space and the space of urban practices in such a way as to make them interrelated and entangled as suggested by de Souza e Silva (2009) and Montola (2005). The city is perceived through a constantly changing digital skin (Rabari \& Storper, 2015), which creates (re)readings of territory and associated activities related to territorial acquisition. The ability for players to propose game elements and support these through the provision of information about physical spaces in the city provides a bottom-up process for VGI, incentivised for players attempting to redefine the game board. A flow of information between the digital and city spaces increasingly aligns them, blurring the boundaries and making them part of the hybridised space. This process contributes to exploration and discovery in the city by making new and additional information about known and unknown places available to the players. The mechanisms for communication and collaboration between players opens up a new dimension of strategic and spatial possibilities for engagement with fellow urban dwellers. The incessant nature of the game results in an increased integration between game time and time dedicated to other everyday practices. Other studies on Ingress have also confirmed this finding in terms of an 'interlacing' with urban life in different ways (Fragoso \& Reis, 2016). The game can be played spontaneously, based on a combination of the location of the player in the city and the need to react to changing conditions in the game.

Altered mobility practices based on engagement with the game can range from minor route alterations on everyday commutes to designated multiplayer excursions towards achieving specific collective objectives. The mode choice for travel and the experience of journeys themselves are affected by the restrictions of the former and the need to physically move through the city in order to make one's avatar move in the virtual interface. 
Altered social practices resulting from the need to align with a faction and work collaboratively to achieve game goals has resulted in the development of external social media-based and physically located networks, which are reinforced through local events, missions and challenges encouraging collective action and differentiated roles.

As a counterpoint to the apolitical analysis of the potential for LBMGs to alter urban practices and facilitate collaborative possibilities, it should be noted that previous research into the case study of Pokémon Go has found that its design reinforces geographic inequalities (Colley et al., 2017), pointing to LBMGs and the need to study their wider effects on the city in this context (de Souza e Silva, 2017; Hjorth \& Richardson, 2017). Concerns related to issues of privacy and surveillance in LBMGs have also been raised. Ingress, specifically, has been labelled a game promoting "datafication in exchange for the gift of play," and has been claimed to exploit gamer communities being dubbed one of the most seductive and "prolific data-mining tools to be introduced in the last decade" (Hulsey \& Reeves, 2014, p. 389). The focus of the analytical framework utilised here is on the use of gameplay mechanisms in producing a hybrid gameplay environment with impacts on social and mobility practices, and engagement with the city, resulting in limitations for direct analysis of political aspects, limitations or bias. An alternative framework could perhaps be better suited to overcome this limitation.

\section{Conclusion}

Mobile communication technologies in cities are increasing, affecting everyday life through the mediation of urban experiences and interactions (Ash, 2015; Castells, 1996; Manovich, 2001; Rabari \& Storper, 2015). The practice of playing Ingress is related to multiple altered urban practices including: mobility in the city, engagement with places, new social networks and collaborative actions. The analytical approach utilised allows the identification of specific mechanisms incorporated into the digital interface and overall game design enabling avenues towards these changes. With the prevalence of LBMGs, the new and altered possibilities for multidimensional interactions between players and the city are relevant for urban management and governance (Rabari \& Storper, 2015; Sengupta, 2017). The increased levels of participation, collaboration and engagement achievable through the intentional design of digital interface components provide possibilities of scale, participation and immersion that 'serious games' in planning have not managed to achieve (Gordon et al., 2011). Lessons can be learnt from Ingress and other HRGs regarding the use of new digital technologies and platforms for awareness, co-evolution, participation and negotiation, in the context of emergent urban futures (Sengupta, 2017).

This article introduces an innovative interdisciplinary approach that can be used to deconstruct LBMG interfaces into analysable components and theorise their effects on urban practices. We have demonstrated the utility of this approach, for comparative studies on other LBMGs and their effects on urban practice. Other issues such as privacy and power relations raised around LBMGs have been largely unaddressed in this article due to its focus and scope, but remain significant and point to additional dimensions of research in this context. The methodological approach taken partly reflects limitations posed by the lack of a formal Application Programming Interface for Ingress at the time of writing. The availability of this feature in the future should allow additional insights through digital traces in the city, and help develop a better understanding of privacy issues. An alternative approach utilising mobile technology data to explore urban community dynamics using GIScience methods can be seen presented by Shelton, Poorthuis, and Zook (2015). A further methodological approach would be to interview and access the developers of LBMGs such as Niantic in our case study, which may help reveal some of the underlying motivations behind the game design. These alternatives, among other approaches, would be complementary to the approach taken in this article and can shed further light on spatial inequalities, how practices of the urban gamers have changed, data privacy, VGI processes, power relations and negative consequences of LBMGs which are beyond the scope of this article.

\section{Acknowledgments}

Special thanks to the AESOP Planning and Complexity thematic group for the conference organized in Lisbon (November 2019), in which insightful feedback was influential for the development of our research. We would also like to thank the editor of the thematic issue and the three anonymous reviewers who provided useful and constructive advice towards improving this article.

\section{Conflict of Interests}

The authors declare no conflict of interests.

\section{References}

Ahlqvist, O., \& Schlieder, C. (Eds.). (2018). Geogames and geoplay: Game-based approaches to the analysis of geo-information. Cham: Springer.

Apperley, T. H., \& Jayemane, D. (2012). Game studies' material turn. Westminster Papers in Communication and Culture, 9(1), 5-25.

Ash, J. (2009). Emerging spatialities of the screen: Video games and the reconfiguration of spatial awareness. Environment and Planning A, 41(9), 2105-2124.

Ash, J. (2013). Technologies of captivation: Videogames and the attunement of affect. Body and Society, 19(1), 27-51.

Ash, J. (2015). The interface envelope: Gaming, technology, power. New York, NY: Bloomsbury Publishing. 
Ash, J., Kitchin, R., \& Leszczynski, A. (2018). Digital turn, digital geographies? Progress in Human Geography, 42(1), 25-43.

Ashtari, D., \& de Lange, M. (2019). Playful civic skills: A transdisciplinary approach to analyse participatory civic games. Cities, 89, 70-79.

Castells, M. (1996). The rise of the network society (Vol. 12). Hoboken, NJ: John Wiley \& Sons.

Colley, A., Thebault-Spieker, J., Lin, A. Y., Degraen, D., Fischman, B., Häkkilä, J., . . . Schöning, J. (2017). The geography of Pokémon Go: Beneficial and problematic effects on places and movement. In Proceedings of the $2017 \mathrm{CHI}$ conference on human factors in computing systems (pp. 1179-1192). New York, NY: Association for Computing Machinery.

de Roo, G., \& Yamu, A. (2017). New ways of conditioning space and place in the dynamic and transformative environments: Liaising between the worlds of matter and the virtual. In C. Yamu, A. Poplin, O. Devisch, \& G. de Roo (Eds.), The virtual and the real in planning and urban design: Perspectives, practices and applications (pp. 11-39). London: Routledge.

de Souza e Silva, A. (2006). From cyber to hybrid: Mobile technologies as interfaces of hybrid spaces. Space and Culture, 9(3), 261-278.

de Souza e Silva, A. (2009). Hybrid reality and locationbased gaming: Redefining mobility and game spaces in urban environments. Simulation and Gaming, 40(3), 404-424.

de Souza e Silva, A. (2017). Pokémon Go as an HRG: Mobility, sociability, and surveillance in hybrid spaces. Mobile Media and Communication, 5(1), 20-23.

de Souza e Silva, A., \& Hjorth, L. (2009). Playful urban Spaces: A historical approach to mobile games. Simulation \& Gaming, 40(5), 602-625.

de Souza e Silva, A., \& Sheller, M. (Eds.). (2014). Mobility and locative media: Mobile communication in hybrid spaces. London: Routledge.

Dodge, M., \& Kitchin, R. (2004). Flying through code/space: The real virtuality of air travel. Environment and Planning A, 36(2), 195-211.

Evans, L., \& Saker, M. (2019). The playeur and Pokémon Go: Examining the effects of locative play on spatiality and sociability. Mobile Media and Communication, 7(2), 232-247.

Fink, E. (1974). The ontology of play. Philosophy Today, 18(2). https://doi.org/10.5840/philtoday19604229

Foth, M., Bajracharya, B., Brown, R., \& Hearn, G. (2009). The second life of urban planning? Using NeoGeography tools for community engagement. Journal of Location Based Services, 3(2), 97-117.

Fragoso, S., \& Reis, B. M. S. (2016). Ludic re-enchantment and the power of locative games: A case study of the game ingress. International Conference on Culture, Technology, and Communication, 490, 131-148.

Gong, H., Hassink, R., \& Maus, G. (2017). What does Pokémon Go teach us about geography? Geographica Hel- vetica, 72(2), 227-230.

Goodchild, M. F. (2007). Citizens as sensors: The world of volunteered geography. Geojournal, 69(4), 211-221.

Gordon, E., \& Baldwin-Philippi, J. (2014). Playful civic learning: Enabling reflection and lateral trust in gamebased public participation. International Journal of Communication, 8(1), 759-786.

Gordon, E., \& Manosevitch, E. (2011). Augmented deliberation: Merging physical and virtual interaction to engage communities in urban planning. New Media and Society, 13(1), 75-95.

Gordon, E., Schirra, S., \& Hollander, J. (2011). Immersive planning: A conceptual model for designing public participation with new technologies. Environment and Planning B: Planning and Design, 38(3), 505-519.

Hjorth, L., \& Richardson, I. (2017). Pokémon GO: Mobile media play, place-making, and the digital wayfarer. Mobile Media and Communication, 5(1), 3-14.

Hulsey, N., \& Reeves, J. (2014). The gift that keeps on giving: Google, ingress, and the gift of surveillance. Surveillance and Society, 12(3), 389-400.

Hunicke, R., LeBlanc, M., \& Zubek, R. (2004). MDA: A formal approach to game design and game research. Proceedings of the AAAl Workshop on Challenges in Game, 4(1), 1722-1726. Retrieved from https://users.cs.northwestern.edu/ hunicke/ MDA.pdf

Kinsley, S. (2014). The matter of "virtual" geographies. Progress in Human Geography, 38(3), 364-384.

Kitchin, R., \& Dodge, M. (2011). Code/space: Software and everyday life. Cambridge, MA: MIT Press.

Klausen, M. (2014). Re-enchanting the city: Hybrid space, affect and playful performance in geocaching, a location-based mobile game. Journal of Urban Cultural Studies, 1(2), 19-213.

Lee, J. H., Keating, S., \& Windleharth, T. (2017). Challenges in preserving augmented reality games: A case study of Ingress and Pokémon GO. In Proceedings of the 14th International Conference on Digital Preservation. Kyoto: Kyoto University. Retrieved from https://ipres2017.jp/wp-content/uploads/44Jin-HaLee.pdf

Lehtonen, T.-K., \& Mäenpää, P. (1997). Shopping in the East Centre Mall. In P. Falk \& C. Campbell (Eds.), The shopping experience (pp. 136-165). London: Sage.

Lutz, C. A., \& Collins, J. L. (1993). Reading national geographic. Chicago, IL: University of Chicago Press.

Manovich, L. (2001). The language of new media. Cambridge, MA: MIT Press.

McLean, J. (2020). Changing digital geographies: Technologies, environments and people. Cham: Springer Nature.

Montola, M. (2005). Exploring the edge of the magic circle: Defining pervasive games. In Proceedings of the digital arts and culture 2005 Conference. Copenhagen: IT University of Copenhagen. Retrieved from https://citeseerx.ist.psu.edu/viewdoc/download? 
doi=10.1.1.125.8421\&rep=rep1\&type=pdf

Niantic. (2018). Welcome to Ingress Prime. Niantic. Retrieved from https://nianticlabs.com/en/blog/ ingress-prime

Niantic. (2020a). Portal network. Niantic. Retrieved from https://www.Ingress.com/support

Niantic. (2020b). What is "Ingress"? Niantic. Retrieved from http://Ingressanime.com/en/Ingress

Poplin, A. (2011). Games and serious games in urban planning: Study cases. In B. Murgante, O. Gervasi, A. Iglesias, D. Taniar, \& B. O. Apduhan (Eds.), Computational science and its applications-ICCSA 2011: Lecture notes in computer science (Vol. 6783, pp. 1-14). Berlin: Springer.

Poplin, A. (2014). Digital serious game for urban planning: “B3-Design your marketplace!" Environment and Planning B: Planning and Design, 41(3), 493-511.

Rabari, C., \& Storper, M. (2015). The digital skin of cities: Urban theory and research in the age of the sensored and metered city, ubiquitous computing and big data. Cambridge Journal of Regions, Economy and Society, 8(1), 27-42.

Rose, G. (2016). Visual methodologies: An introduction to the interpretation of visual materials (4th ed.). Newcastle upon Tyne: Sage.
Sengupta, U. (2017). ICT, open data and the Internet of Things: Potential future trajectories in urban planning. In G. de Roo, C. Yamu, O. Dewisch, \& A. Poplin (Eds.), The virtual and the real in planning and urban design: Perspectives, practices and applications (pp. 69-90). London: Routledge.

Shaw, I. G. R., \& Warf, B. (2009). Worlds of affect: Virtual geographies of video games. Environment and Planning $A, 41(6), 1332-1343$.

Sheller, M., \& Urry, J. (2006). The new mobilities paradigm. Environment and Planning A, 38(2), 207-226.

Shelton, T., Poorthuis, A., \& Zook, M. (2015). Social media and the city: Rethinking urban socio-spatial inequality using user-generated geographic information. Landscape and Urban Planning, 142, 198-211.

Winter, S., Richter, K. F., Baldwin, T., Cavedon, L., Stirling, L., Duckham, M., . . . Rajabifard, A. (2011). Locationbased mobile games for spatial knowledge acquisition. CEUR Workshop Proceedings, 780, 1-8.

Zook, M. A., \& Graham, M. (2007). Mapping DigiPlace: Geocoded internet data and the representation of place. Environment and Planning B: Planning and Design, 34(3), 466-482.

\section{About the Authors}
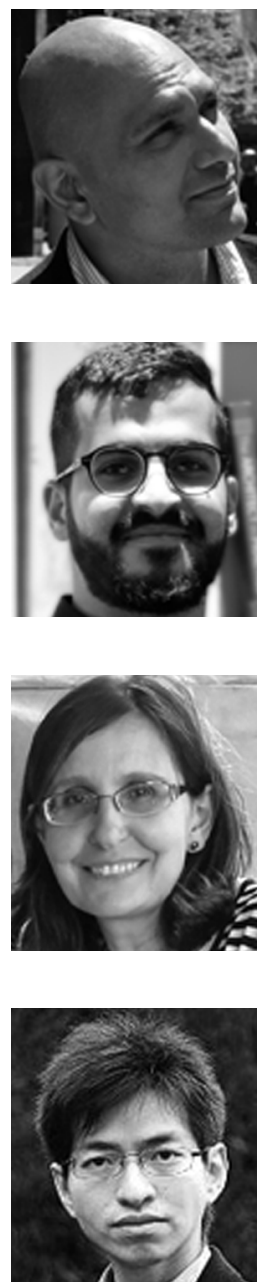

Ulysses Sengupta is a Reader at the Manchester School of Architecture (Manchester Metropolitan University). Sengupta is the founding director of the Complexity Planning and Urbanism research laboratory [CPU]Lab and leads the master's design atelier [CPU]Ai. He uses a complexity framework for transdisciplinary research between design, natural and social sciences. This involves new digital tools, computational thinking and urban theory addressing urban transformations. His research spans future cities, smart cities, the Internet of Things, agile governance and cities as complex adaptive systems (CAS).

Mahmud Tantoush is a PhD candidate at the Department of Architecture and researcher with the Complexity Planning and Urbanism research laboratory [CPU]Lab at the Manchester Metropolitan University. His PhD research analyses and links Volunteered Geographic Information and other forms of urban data to understand how cities function in relation to urban morphology on different temporal and spatial scales. His interests lie in computational design, smart cities, big data, geographic data science, urban morphology and complexity theories.

May Bassanino has over 15 years' experience in conducting and delivering interdisciplinary projects in the areas of collaborative engineering, process modelling and evaluation frameworks. This expertise has been applied to a variety of domains including construction, ecosystem, social, design and energy. May joined the Complexity Planning and Urbanism research laboratory [CPU]Lab at the Manchester School of Architecture (Manchester Metropolitan University) as a Project Manager and Researcher in 2019 and has been working in the area of urban complexity research since then.

Eric Cheung is a fully qualified architect in the UK and a Researcher at the Manchester School of Architecture (Manchester Metropolitan University). His research attempts to answer old problems with new methods for urban-transport integrated spatial design and planning, drawing on and contributes to known theoretical frameworks and new computational techniques. This involves the investigation and construction of advanced computational methods and tools to understand urban-transport systems and to explore the multi-dimensional decision space for alternative spatial solutions. 